\title{
To the Problem of Future Specialists Regulatory Legal Culture in the Sphere of Social Tourism Formation
}

\author{
Kuznetsov S.A. \\ University of Management "TISBI" \\ Naberezhnye Chelny, Russia \\ stanislav.kuznetsov.79@mail.ru
}

\author{
Maksimova E.F. \\ University of Management "TISBI" \\ Naberezhnye Chelny, Russia \\ Kzm_diss@mail.ru
}

\begin{abstract}
The basis of the legal and regulatory training in the system of higher education, especially in the Universities of non-legal profile consists of knowledge system about the law, as the main mechanism of the individual, society and state relationship, as well as actions aimed at their implementation, which provides legal and regulatory professional competence of any profile specialist. Many researchers note a low level of specialists legal conciousness in the sphere of social tourism formation, ignorance of legal acts, which does not allow them to fully exercise their duties in accordance with professional requirements. The article presents the results of studies in which the methodological, theoretical and technological bases of regulatory legal culture of social tourism future specialists formation were developed. Research methods: pinging, questionnaires (methodology named after T.A. Firosova, "Collective assessment of legal consciousness"), the ranking (method of studying value orientations of $M$. Rokich), observation, peer review, a survey (J. Tapp and F. Levin) confidence diagnostics on Rosenberg scale, rapid questionnaire "Tolerance index". The article gives a theoretical and methodological basis and technological support of the future specialists regulatory legal culture formation in the sphere of social tourism. A conceptual model of regulatory legal training is developed and the technology of regulatory legal culture of social tourism industry future specialists is developed and proved. The model of regulatory legal culture of the future specialists in the sphere of social tourism developed by us includes interconnection of modules: methodological, target, diagnostic, prognostic, meaningful, praxeological, organizational, effective. The model reflects the sequence of regulatory legal training stages of social tourism sphere future specialists: propaedeutic, diagnostic prognostic, forming - productive, estimated - final. Thus, a comprehensive study of the future social tourism industry specialists legal culture formation problem was not previously subjected to systematic study in social, procedural and general pedagogical contexts.
\end{abstract}

Keywords-technological bases; legal culture; research; methodology; professional requirements; regulatory legal; training.

\section{INTRODUCTION}

The priorities in the socio-economic sphere of the Russian state are socially oriented at economy, education that meets the needs of the individual, civil society development. The basis for the implementation of government priorities in all spheres of public life is regulatory legal basis of the government and citizens' life.

Fundamental documents that provide the regulatory legal basis for education in Russia are: a long-term concept of Russia's social and economic development for the period until 2020, the National Doctrine of Education in the Russian Federation until 2025. They emphasize that the Russian education system must make the transition from the mass education system, typical to the industrial economy, to the necessary innovation to create a socially oriented economy continuous individualized education for all, focused on the formation of creative socially responsible person; the main priorities of the national education system development are: continuous education, continuity of the education levels and stages, fundamentalization of education in conjunction with an application orientation; under the rule of law, the role of law in social controls system, there is a strengthening of legal principles in the behavior of people in society and the state.

The Principles of the Russian Federation State Policy in the sphere of legal literacy and legal awareness of citizens (2011) identified the most important areas: "The development of teaching practice, the basics of law in the educational institutions of different types and species, Various options of legal education regional models support, training courses development, including legal issues, relevant educational programs, teaching and learning aids, as well as increasing legal literacy of teachers, conducting research and experimental work for the purpose of scientific and methodological support of legal education. "

Research problem: what are the methodological, theoretical and technological bases of the future specialists in the sphere of social tourism legal culture formation.

The purpose of the study is to develop a theoretical and methodological basis and technological support of the future social tourism industry specialists legal culture process formation. 
The object of study - social training of tourism specialists.

Subject of research - theoretical and methodological basis and technological support of the future specialists in the sphere of social tourism legal culture formation process.

In accordance with the purpose of the following research objectives were put:

1. Justify the set of provisions that make up the theoretical and methodological background of the investigated problem.

2. Identify the content, methods and organizational bases of research.

3. Disclose the nature and content of tourism social sphere specialists legal culture technology formation process.

4. Develop a conceptual model of future social tourism industry specialists legal training technology formation.

5. Create and experimentally prove social tourism industry specialists' future legal culture technology formation.

\section{RESEARCH METHODOLOGY}

The following methods were used during the research: theoretical - literature analysis, modeling research hypothesis; Empirical - the study of the pedagogical documentation and results of operations, surveillance, survey, method of expert evaluations, testing, generalization of pedagogical experience, an experienced pedagogical work, experiment; statistics ranking, rating evaluation, mathematical and statistical analysis of the survey results.

The basis of the study was Naberezhnye Chelny branch FGBOY VPO «Povolzhskaya State Academy of Physical Culture, Sport and Tourism." The survey covered 610 students at different stages of research, including 383 - students of experimental and control groups.

The pedagogical research was carried out in the following stages: (propaedeutic, search, design, process steps) in the period from 2006 to 2015 on the basis of Naberezhnye Chelny branch of the "Povolzhskaya State Academy of Physical Culture, Sport and Tourism." The control group consisted of students enrolled in high school in 2008, and a pilot one - in 2009.

Students of the following disciplines participated in the experimental work: 032103.65 Recreation and sports tourism (qualification - Recreation Officer and sports tourism); 100101.65 Service (qualification - specialist in service); 032102.65 Physical education for persons with health deviations (adaptive physical education), (qualification specialist in adaptive physical education); 032101.65 Physical culture and sport (qualification - specialist in physical culture and sport). Graduates of these specialties can and tend to work in the field of social tourism.

Based on the presented essence-content characteristics of social tourism sphere specialists legal culture, we gave it a criterion characteristic.
To the cognitive component of social tourism sphere specialist legal culture presented by the legal framework of knowledge system in the field of social tourism, improving and adaptive physical training, health and safety; peculiarities of legal and economic relations between the participants in the field of social tourism, corresponds the gnostic-cognitive test. The indicators of this criterion are: the volume of knowledge system data, sustainability of knowledge, willingness to further assimilation of regulatory knowledge.

To the emotional and evaluative component comprising a set of social and legal views, which are a way of thinking, an individual point of view with regard to rules and regulations of vulnerable segments of the population meets the emotive criterion. The indicators are the presence of its ability to experience positive emotions but about the positive effects of legal reality and negative - due to negative; adequate assessment of the effects of legal reality in terms of legality, expediency.

The behavioral component containing social and legal systems - behavioral position, ready for a certain model of legal behavior in relation to vulnerable segments of the population, is determined by the axiological criterion. Its indicator is the internalization of regulatory requirements in the sphere of personal values.

Activities component is represented by a set of social and legal skills to develop their own regulations to ensure the quality and standardization of services to the tourism industry, including services to improve the health and physical adaptation of tourists; prepare contract documents for all counterparties of tourist activity; to assess compliance with quality standards at the enterprises of the tourism industry, in accordance with regulatory requirements and the specific needs of service users of social tourism; to use specific means of communication of people with disabilities, allowing to realize their rights, corresponding to a practical test, its performance are: the construction of the algorithm implementation of operations specific actions in the structure of skills, simulation (planning) the practical implementation of actions that make up this skill, perform complex actions, components of this skill, self-analysis of the results following the steps that make up the skill in relation to the purpose of the activities.

Personal component comprises an inner desire and willingness of the individual to the development of a legal culture and the ability to manifest the spiritual immune system to the needs and social needs of vulnerable segments of the population. This component corresponds to the reflexive criterion, indicators are capability to empathy and trust, tolerance, culture of behavior, reflecting the ratio of the norms, values and traditions of society, civic responsibility and initiative.

We have developed and theoretically grounded concept of future social tourism industry specialists legal training, its technological support in the form of the legal culture formation model of the future social tourism sphere specialists. 
The model of the future specialists legal culture formation in the sphere of social tourism includes the interconnection of modules: methodological, target, diagnostic, prognostic, meaningful, praxeological, organizational, effective. The model reflects the sequence of social tourism future specialists legal training steps: propaedeutic, diagnostic and prognostic, forming-productive, assessment and final.

\section{RESULTS}

Complex research methods were used for diagnostic examination. To investigate the level of the cognitive component formation the test survey of emotionallyassessment - questionnaires (methodology TA Firosova "Group assessment of legal consciousness") was used , axiological - ranking (method of studying value orientations M. Rokich), the activity - observation, peer review , a survey (by J. Tapp and F. Levin.), personal - study empathic personality traits by Boyko, rapid diagnosis of confidence on a scale of Rosenberg, express questionnaire "tolerance index", a questionnaire with questions formulated in the form of projective situations and unfinished sentences.

Based on the data obtained, all students were divided according levels of the legal culture formation.

The high level of social tourism sector specialist legal culture formation is characterized by: deep, full knowledge about the legal framework of social tourism, characteristics of the legal and economic relations between the participants of tourist activity, legal, regulatory, technical and organizational foundations of life safety; strong abilities to independently develop regulations to ensure the quality and standardization of the tourism industry services, constitute the legal documentation for all counterparties of tourist activity, to assess compliance with quality standards at the enterprises of the tourism industry regulatory requirements; valuemotivational relation to professional legal work. Technological process of social tourism sector future specialists legal culture formation starts with the definition of initial parameters of the research subject, which in consequence will change under the influence of a particular job. The subject of our research are the components of the legal culture.

The average level of social tourism sector specialist legal culture formation is characterized by: incomplete, fragmentary knowledge of the basics of the legislation on social tourism, especially legal and economic relations between the participants of tourist activity, legal, regulatory, technical and organizational foundations of life safety; individual skills (independently develop regulations to ensure the quality and standardization of services to the tourism industry, constitute the legal documentation for all counterparties of tourist activity, to assess compliance with quality standards at the enterprises of the tourism industry regulatory documentation requirements); situational relation to professional legal activity, which manifests itself in the intention to comply with ethical and legal standards to use the regulatory and legal documents in tourist activity, depending on the circumstances.
The low level of social tourism sector specialist legal culture formation is characterized by: lack of knowledge about the legal framework of social tourism, the characteristics of the legal and economic relations between the participants of tourist activity, legal, regulatory, technical and organizational foundations of life safety; poorly formed abilities to independently develop regulations to ensure the quality and standardization of services to the tourism industry, constitute the legal documentation for all counterparties of tourist activity, to assess compliance with quality standards at the enterprises of the tourism industry regulatory requirements; indifferent attitude to the professional legal activity. It manifests itself in an indifferent attitude to the ethical and legal standards, the use of normative and legal documents in tourist activity.

Summary data on the levels of tourism social sphere future specialists legal culture formation on the ascertaining stage of the pilot study are presented in Table I.

TABLE I. LEVELS OF TOURISM SOCIAL SPHERE SPECIALISTS LEGAL CULTURE FORMATION ON THE ASCERTAINING STAGE OF THE EXPERIMENTAL RESEARCH

\begin{tabular}{|c|c|c|c|c|}
\hline \multirow{2}{*}{ Levels } & \multicolumn{2}{|c|}{ Experimental group } & \multicolumn{2}{c|}{ Control group } \\
\cline { 2 - 5 } & $\begin{array}{c}\text { Abs. } \\
\text { Quantity }\end{array}$ & $\%$ & $\begin{array}{c}\text { Abs. } \\
\text { Quantity }\end{array}$ & $\%$ \\
\hline High & 19 & 10,0 & 19 & 9,8 \\
\hline Average & 75 & 39,7 & 84 & 43,3 \\
\hline Low & 95 & 50,3 & 91 & 46,9 \\
\hline
\end{tabular}

Diagnosis of tourism social sphere specialists legal culture formation on the ascertaining stage of experimental research showed that only about $10 \%$ of the students had a high level (10.0 - in the experimental group, 9.8\% - in the control one), about $40 \%$ - medium $(39.7 \%$ - in the test group 43.3 - in the control one) and about $50 \%$ - is low (50.3\% - in the experimental group and $46.9 \%$ - in the control one).

An important place in the formative stage of the experimental work took significant socio - community service of students - future social tourism industry specialists as one of the ways of high school educational space organization. Traditional socially oriented associations and educational institutions are various organizations, societies, clubs, associations, teams, groups and other formations.

All activities of the Student Council are socially valued: educational and research sector - CHO "Terra"; sector of military-patriotic education and SSB "Outpost"; the information sector - edition of the student newspaper; sector of the volunteer movement and student labor groups; cultural and recreational sector; the sports sector, the tourist club "SKIF", "Disabled Sports Club Yuldash".

The main pedagogical conditions on the forming stage of the future social tourism industry specialists legal culture formation process were:

- Updating the content of invariant disciplines questions of legal regulation preparation in the sphere of social tourism;

- Inclusion into the variable part of future specialists in the sphere of social tourism training curricular subjects "Legal social tourism bases", "The legal culture of social tourism 
industry specialists", "Normative-legal bases of the barrierfree environment organization", "Norms and rules of conduct and communication with people with disabilities", "Relief-dot system of Braille", "Sign language";

- Use of active and interactive forms of learning in the legal training, simulating real conditions of professional activity in the sphere of social tourism;

-Students inclusion in a variety of socially significant public benefit activities undertaken on the basis of free choice of the student, both independently and with the active participation of others (teachers and students).

At the end of our research formative stage diagnostics of the future tourism social sphere specialists legal culture formation was again carried out. For this purpose, the same procedures as in the ascertaining step research were used.

Analysis of the data (Table 2), showed that between indicators of control and experimental groups, there is a significant difference, because a high level of the legal culture formation in the control phase of the experimental group have $38.6 \%$ of students, in the control group - only $13.4 \%$; at a low level, there are $16.4 \%$ of future social tourism industry specialists, students studying in the experimental group and $41.8 \%$ - in the control group; and only the average level has almost the same number of students in the experimental and control groups: $45 \%$ and $44.8 \%$ - respectively.

TABLE II. LEVELS OF FUTURE TOURISM SOCIAL SPHERE

SPECIALISTS LEGAL CULTURE FORMATION ON THE

ASCERTAINING STAGE OF THE EXPERIMENTAL RESEARCH

\begin{tabular}{|c|c|c|c|c|}
\hline \multirow{2}{*}{ Indicators } & \multicolumn{2}{|c|}{ Experimental group } & \multicolumn{2}{|c|}{ Control group } \\
\cline { 2 - 5 } & $\begin{array}{c}\text { Abs. } \\
\text { Quantity }\end{array}$ & $\%$ & $\begin{array}{c}\text { Abs. } \\
\text { Quantity }\end{array}$ & $\%$ \\
\hline High & 73 & 38,6 & 26 & 13,4 \\
\hline Average & 85 & 45,0 & 87 & 44,8 \\
\hline Low & 31 & 16,4 & 81 & 41,8 \\
\hline
\end{tabular}

Pictures 1 and 2 the results of the research ascertaining and control stages are clearly represented.

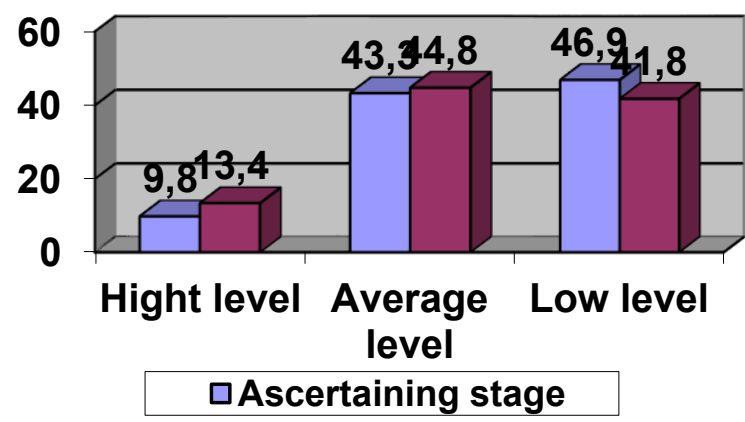

Fig. 1. Distribution of the control group students according to the legal culture formation levels

Analyzing the data shown in picture 1, we came to the conclusion that in the control group, there were changes in the legal culture formation level, but this is typical only for a small number of students.

Analysis of the data presented in picture 2, allowed us to conclude that only $16.4 \%$ of the experimental group students have no changes in the legal culture formation level, the rest of students have positive changes.

In order to improve the reliability evaluation process of the tourism social sphere future specialists legal culture formation and evaluate the effectiveness of our pedagogical influence on this process, we used the $\chi$ - criterion.

Our values in the control group (1.9) is much smaller, and in the experimental (105.3) - significantly more than the corresponding table value $\mathrm{m}-1=2$ degrees of freedom, constituting 13.82 with permissible error probability less than 0.001 .

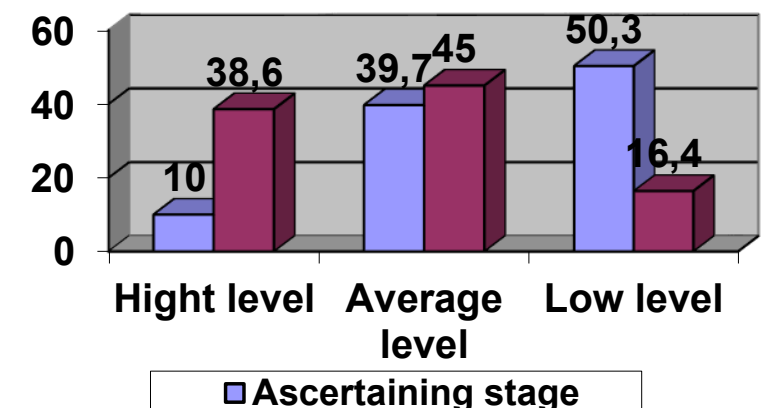

Fig. 2. Distribution of the experimental group students according to the legal culture formation level

Therefore, the hypothesis of the significant changes that occurred with the future social tourism industry specialists, students of the experimental group, as the formative experiment result, was confirmed.

\section{CONCLUSION}

Thus, a comprehensive research of the future social tourism industry specialists legal culture formation problem is carried out, which was not previously subjected to systematic study in social, procedural and general pedagogical contexts;

- Methodological approaches of the future of social tourism industry specialists legal culture formation are scientifically substantiated (system, axiological, competence, civilizational and socio-contextual);

- The essence and content of the regulatory - legal culture of social tourism industry specialists as an integrative education of the person, represented by a set of regulatory and socio-legal knowledge, skills, attitudes and social and legal systems, as well as the individual qualities, allowing the social tourism sector specialist to design and implement professional activities aimed at ensuring the quality and safety standards of complex tourist service vulnerable segments of the population are revealed;

- The concept of future social tourism industry specialists legal training is developed, which is a set of science-based ideas, principles, direction and content of the legal and regulatory training in high school, due to the rules of civil society, including regulatory system, in accordance with which the process of training and education is designed and carried out; 
[5] Kuznetsov S.A. Socio-psychological training of the tourism social

- A model of the future social tourism industry specialists legal culture, based on the relationship of modules (methodological, target, diagnostic, prognostic, meaningful, praxeological, organizational, productive) is set up , implemented and built taking into account the features of social tourism industry specialists professional work, aimed at ensuring the quality and safety standards of complex tourist service vulnerable segments of the population.

\section{References}

[1] Kuznetsov S.A. Essential-substantial characteristics of social and legal competence of the future experts in physical training and sports. Omsk Scientific Bulletin. 2010, 6(92), pp. 176-178.

[2] Kuznetsov S.A. Future specialists social and legal competence formation in physical training and sports. Scientific notes of the Physical Education University named after P.F. Lesgaft. 2011, 1, pp. 58-60.

[3] Kuznetsov S.A. Criteria and indicators of the future specialists social and legal competence formation in physical training and sport. Pedagogico-psychological and medico-biological problems of physical culture and sports. 2011, 1(18). URL: http: // www.kamgifk.ru/magazin/n 15.htm/.

[4] Kuznetsov S.A. The nature and specifics of social tourism as a form of social support for the poor. Proceedings of the Southern Federal University. Jurisprudence. 2013, 3, pp. 27-37.
Psychology. 2013, 2, pp. 177-182.

[6] Kuznetsov S.A. Meaningful social activities characteristic of tourism specialists (specialty RISOT). Pedagogico-psychological and medicobiological problems of physical culture and sport. 2013, 2(27). URL: http: // www.kamgifk.ru/magazin/n 15.htm /.

[7] Kuznetsov S.A. Methodological basis of the person legal culture formation process. Law and Education. 2013, 10, pp. 39-46.

[8] Kuznetsov S.A. Legal culture specialists in the field of adaptive physical culture, sport and tourism. Theory and Practice of Physical Culture. 2013, 10, pp. 36-43.

[9] Kuznetsov S.A. Theoretical approaches to the design of future specialists legal training in the sphere of social tourism. Pedagogicopsychological and medico-biological problems of physical culture and sport. 2013, 3(28). URL: http: // www.kamgifk.ru/magazin/n 15 htm /.

[10] Kuznetsov S.A. On the question of tourism social sphere future specialists legal culture formation diagnostics. Pedagogicopsychological and medico-biological problems of physical culture and sport. 2014, 3(32), pp. 52-60. DOI: 10.14526/08_2014_09.

[11] Kuznetsov S.A. On the issue of future social tourism industry specialists legal culture technology formation in high school of physical education and sport. Pedagogico-psychological and medico-biological problems of physical culture and sport. 2015, 2(35), pp. 79-88. DOI: 10.14526/01_1111_12. 